\title{
Delusional Misidentification Incident in a Right Hemisphere Stroke Patient
}

\author{
ANDREW W. YOUNG, ${ }^{1}$ BRENDA M. FLUDE ${ }^{2}$ and ANDREW W. ELLIS ${ }^{3}$ \\ ${ }^{1}$ Department of Psychology, University of Durham, Durham DH1 3LE, UK \\ ${ }^{2}$ Department of Psychology, University of Lancaster \\ ${ }^{3}$ Department of Psychology, University of York
}

\begin{abstract}
We report a delusional misidentification incident lasting some hours in which a man who had suffered a right hemisphere stroke, HW, mistook a student for his daughter. Investigation of HW's face processing abilities showed unimpaired ability to recognize familiar faces and match facial expressions, but severe impairments of unfamiliar face matching both on the Benton test and a task requiring the matching of disguised and undisguised faces. The incident shows some similarity to the Frégoli delusion, which has also been noted following brain injury affecting the right cerebral hemisphere.
\end{abstract}

\section{Introduction}

There is increasing evidence of organic involvement in delusional misidentification (Joseph, 1986). Brain injuries have been demonstrated in all of the major delusional misidentification syndromes: Capgras' delusion, in which certain people are felt to have been replaced by "dummies" or imposters, the Frégoli delusion, in which a cunningly disguised persecutor is claimed to be following the patient about, and intermetamorphosis, in which a particular person's appearance seems to the patient to transform into that of someone else (e.g. de Pauw et al., 1987; Joseph, 1987; Lewis, 1987).

Investigations of the face processing abilities of DMS patients have provided some evidence of impairment. For example, Capgras' patients are often poor at unfamiliar face matching tasks (Luaute et al., 1978; Shraberg and Weitzel, 1979; Morrison and Tarter, 1984; Tzavaras et al., 1986). However, the interpretation of these findings is limited by the fact that problems in unfamiliar face matching are only one of a number of dissociable face processing impairments which can be observed after brain injury. In particular, dissociable impairments of familiar face recognition, unfamiliar face matching, and recognition of emotional facial expressions have been described (for reviews, see Bruce and Young, 1986; Young and Bruce, 1991). To date, only one investigation of face processing impairments in delusional misidentification patients has made use of tasks which can tap each of these dissociable abilities (Young et al., 1990).

In the present paper, we describe a form of delusional misidentification which occurred in a patient who had suffered a right hemisphere stroke, and report his performance on face processing tasks identical or similar to those 
previously used in the investigation of delusional misidentification by Young et al. (1990).

\section{Case Description}

HW, a right handed man aged 67, had suffered a right hemisphere stroke. On admission to hospital, he showed left hemiplegia, but was conscious and did not have any speech defect. In the weeks prior to the stroke he had suffered a number of episodes involving clumsiness and weakness of the left hand, and "personality changes" (mood). These were thought to reflect transient ischaemic attacks.

HW was discharged from hospital 2 weeks later, after showing some improvement with physiotherapy. However, he showed persistent left-sided neglect, and was referred to us some 6 months later for this reason. A student given the task of investigating his visuospatial neglect visited him a few times during a 2-month period, and noted neglect in cancellation and drawing tasks (Albert, 1973; Heilman, 1979), but no evidence of neglect in reading text or single words. There was still some left-sided motor weakness, but no evidence of a left visual field defect on confrontation testing.

\section{Misidentification Incident}

During one of the student's visits to HW, an extraordinary incident occurred. When she arrived at his house, he was waiting for her at the door as she drove up, and remarked that for a minute he had thought she was someone else. A few minutes later, he asked "Where did you have your hair done? Was it someone at school?"

The student's attempts to explain to HW that this was her natural hair colour met with the response that "it was blonde this morning". Gradually, it became clear that he was under the impression the student was his daughter. Despite protesting her real identity, she was given the jobs of helping to retrieve an electric fire from the loft, replacing a light bulb, making tea, and even cutting his fingernails.

Trying to convince HW that she was not his daughter only made matters worse for the student, since he became increasingly irritated by the "deception" he thought his daughter was attempting in claiming to be our student. He was cross that she had "stolen" someone else's library card and bank statement, and confiscated them to return to their proper owner. Returning to the topic of the hair colour, he drew attention to photographs of his daughter and said "Look, I told you your hair was blonde this morning. You can't fool me, there are too many pictures of you [up] in here". When asked to do the tests she had brought, HW replied "Not now love, I want to watch the television. Stop bothering me". After further persuasion, he carried out some tasks, but then announced that "You know, you're quite good at this. Well, you're at least as good as J ... [the student]. You should do something like this when you leave school". This led to a 
harangue about truancy, and that her "mum" would have to talk to her when she got home from work.

After more than 3 hours, during the whole of which HW consistently maintained that she was his daughter, the student managed to persuade him to allow her to go, though he was reluctant to let her leave by car, since "you haven't passed your test yet".

The student rang HW's wife the next day, to clear up any further ramifications. His wife confirmed that when she got home from school her daughter had indeed been accused of lying, stealing someone else's identification, playing truant, and driving a blue car before she had passed her test. To the best of her knowledge, HW had never done anything like this before.

Two weeks later, the student visited HW accompanied by one of the authors. He remembered the incident, and was able to describe it in detail. Although he did not this time accuse the student of being his daughter, he seemed to retain some suspicion about the matter, and was not in the least apologetic. The opportunity was taken to carry out tests of HW's face processing abilities.

\section{Face Processing Abilities}

Tests were given to assess HW's ability to identify familiar faces, to match unfamiliar faces, and to determine facial expression. The results are summarized in Table 1.

\section{Identification of familiar faces}

HW was shown 20 highly familiar faces, 20 moderately familiar, and 20 unfamiliar faces, presented one at a time in random order. For each face he was asked whether or not it was a familiar person and, if so, his or her occupation and name. Control data were taken from 28 men of comparable age (65-75 years) from a series of normal men tested at the Radcliffe Infirmary, Oxford (de Haan et al., 1991). The task has previously been used in the investigation of delusional misidentification by Young et al. (1990). The data of interest concern ability to give correct occupations and names to the 20 highly familiar faces, and the rate at which the 20 unfamiliar faces were misidentified. Data for the moderately familiar faces are not included in Table 1, because the control subjects showed high variance in their responses to these.

Results showed normal ability to identify familiar faces for $\mathrm{HW}$. $\mathrm{He}$ scored as well as controls for both occupations and names of highly familiar people, and showed no tendency to misidentify any of the unfamiliar people (20/20 correct rejections).

\section{Unfamiliar face matching}

Two tests of unfamiliar face matching were used, as in Young et al.'s (1990) previous investigation of delusional misidentification. 
TABLE 1. HW's performance of face processing tasks, and means and standard deviations for control subjects of comparable age

\begin{tabular}{llll}
\hline & $H W$ & \multicolumn{2}{c}{ Controls } \\
\cline { 3 - 4 } & & Mean & $S D$ \\
\hline Identification of familiar faces & & & \\
High familiarity faces & & & \\
$\quad$ Occupation: & $19 / 20$ & $18 \cdot 86$ & $1 \cdot 15$ \\
$\quad$ Name: & $17 / 20$ & $16 \cdot 25$ & $2 \cdot 81$ \\
Unfamiliar faces & & & \\
$\quad$ Correct rejections: & $20 / 20$ & & \\
Unfamiliar face matching & & & \\
$\quad$ Benton test: & $35 / 54^{*}$ & $44 \cdot 22$ & $3 \cdot 07$ \\
$\quad$ "Disguise" task: & $11 / 24 * *$ & $22 \cdot 30$ & $2 \cdot 16$ \\
Facial expressions & & & \\
$\quad$ Matching: & $30 / 32$ & $29 \cdot 79$ & $1 \cdot 67$ \\
\hline
\end{tabular}

$*=$ more than $2.5 \mathrm{SDs}$ below control mean

$* *=$ more than $4 \cdot 0 \mathrm{SDs}$ below control mean

First, the Benton Test of Facial Recognition (Benton et al., 1983). In this test, subjects have to choose which of six photographs of unfamiliar faces are pictures of the same person as a simultaneously presented target face photograph. The test includes items involving choice of identical photographs and transformations of orientation or lighting, which are pooled into an overall composite score.

HW was very slow and hestitant on the Benton test. His overall score (35/54 correct) was impaired both in terms of the test's norms and in comparison to a group of 32 men of comparable age tested at the Radcliffe Infirmary (see Table 1). The breakdown of his scores on the subparts of the test was $6 / 6$ correct for identical matches, 11/24 for orientation transformations, and 14/24 with transformed lighting. The accurate performance with identical matches is important, because it shows that HW's poor overall performance was not simply a consequence of failure to attend to faces on the left of the test display because of his unilateral neglect. Appropriate cues were given when necessary, to make sure that $\mathrm{HW}$ examined each of the faces in the display, and his accurate performance at matching identical faces shows that this was effective. The poor overall performance thus reflects a genuine deficit on the unfamiliar face matching task.

The second unfamiliar face matching test examined ability to match disguised faces. Two separate test sheets were used, each showing a $3 \times 4$ matrix of faces in which each of the four faces in the top row appeared three times in disguised or undisguised forms elsewhere on the sheet (see Young $e t$ al., 1990, for an illustration). HW was severely impaired at matching these faces $(11 / 24$ correct) in comparison to the 10 controls of comparable age (range, 63-75 years) from Young et al.'s (1990) study. 


\section{Facial expressions}

HW was shown pairs of photographs of faces of two different people (presented simultaneously), and asked to decide whether or not they had same or different facial expressions. Sixteen of the pairs had the same expressions, and 16 different expressions. HW's performance (30/32 correct) was unimpaired in comparison with that of 34 men of comparable age from the Radcliffe Infirmary series.

\section{Discussion}

HW maintained that our student was his daughter, and continued to act in accordance with this belief for several hours, despite disconfirmatory evidence. The incident bears some resemblance to the Frégoli delusion, in which a persecutor is claimed to have adopted a cunning disguise. The parallel lies in the claim that a seen person is actually someone other than they might appear to be. However, it is not an exact parallel. Although HW maintained that his "daughter" had changed her hair colour, he did not directly imply that she had done this in order to trick him, and he did not seem to feel that she was trying to persecute him or surreptitiously observe him. The only way in which he thought his "daughter" was trying to deceive him was in pretending to be someone else (i.e. our student), which he seemed to consider a joke taken much too far, and he did not suggest that she had made any change to her appearance other than the hair colour. Indeed, the "deception" was initially revealed only because the student insisted she was not HW's daughter. Had she not done this, we can only presume that he would have accepted her as his daughter whilst the incident lasted.

Although not exact, then, the parallel with the Frégoli delusion is interesting because the Frégoli delusion has also been found to occur in the context of a right hemisphere lesion (de Pauw et al., 1987). We cannot of course be certain that his right hemisphere stroke played a direct causal role in the production of this incident for HW, but it is noteworthy that he had experienced TIAs, and that he had not previously suffered from delusional misidentification. The possibility that the incident was related to the stroke itself or a further TIA must thus be seriously considered.

Investigation of HW's face processing abilities showed unimpaired ability to recognize familiar faces and match facial expressions, but severe impairments of unfamiliar face matching both on the Benton test and our "disguise" task. In GC, a case of Frégoli delusion following cerebral infarction we were able to investigate, there was also a severe impairment on the "disguise" matching task and no impairment of expression processing (Young et al., 1990). GC and HW differed, however, in that GC showed some impairment in our test of identification of familiar faces whereas HW was quite normal at this, and in that HW was impaired on the Benton test, which GC performed normally.

Ellis and Young (1990) drew attention to the similarity between the Frégoli delusion and an error all of us make from time to time in everyday 
life. When we expect to meet a particular person, we will occasionally misidentify someone else as that person (Young et al., 1985). However, we usually quickly correct this mistake when inconsistent evidence is picked up (typically, by getting a better view of the person in question). Even so, there are rare occasions when we have to apologize after greeting a stranger. In Frégoli cases, and for HW, though, inconsistent evidence proves insufficient to alter the misidentification. As Ellis and Young (1990) emphasize, this must involve impaired decision mechanisms, which means it may well be more than a coincidence that both GC and $\mathrm{HW}$ were poor at disentangling the effects of disguise.

In making this point, we do not seek to claim that the face processing impairments observed in such cases are in themselves sufficient to cause the delusions. This seems most unlikely, given that face processing impairments are quite a common consequence of right cerebral injury (Ellis, 1983; Benton, 1990), and hence many patients with impaired face processing abilities do not seem to suffer delusional misidentification.

Instead, the face processing impairments may play a role in allowing the delusions to take such a strong hold, since they will make it harder to arrive at contradictory evidence, especially when impaired decision mechanisms are involved (Young et al., 1990). In addition, an intriguing possibility is that delusional misidentification reflects particular combinations of impairments (e.g. Lewis, 1987), as has been argued for the related problem of reduplicative paramnesia (Kapur et al., 1988). On this view, HW's case could involve some but not all of the components that contribute to the fullblown Frégoli delusion.

\section{Acknowledgements}

This research was supported by an ESRC programme award for a multicentred investigation into face recognition (funded as grants XC15250001 to Vicki Bruce at Nottingham University; XC15250002 to Ian Craw at Aberdeen University; XC15250003 to Hadyn Ellis at University of Wales College of Cardiff, XC15250004 to Andy Ellis and Andy Young at Lancaster University; and XC15250005 to David Perrett at St Andrews University). We are grateful to the Press Association and the Lancashire Evening Post for help in finding suitable photographs for use as stimuli. We thank Dr Freda Newcombe for permission to use control data collected for her own investigations.

\section{References}

Albert, M. L. (1973). A simple test of visual neglect. Neurology, 23, 658-664.

Benton, A. L. (1990). Facial recognition 1990. Cortex, 26, 491-499.

Benton, A. L., Hamsher, K. de S., Varney, N. and Spreen, O. (1983). "Contributions to Neuropsychological Assessment: a Clinical Manual". Oxford University Press, Oxford. Bruce, V. and Young, A. (1986). Understanding face recognition. British fournal of Psychology, 77, 305-327. 
De Haan, E. H. F., Young, A. W. and Newcombe, F. (1991). A dissociation between the sense of familiarity and access to semantic information concerning familiar people. European Journal of Cognitive Psychology, in press.

De Pauw, K. W., Szulecka, T. K. and Poltock, T. L. (1987). Frégoli syndrome after cerebral infarction. Journal of Nervous and Mental Disease, 175, 433-438.

Ellis, H. D. (1983). The role of the right hemisphere in face perception. In "Functions of the Right Cerebral Hemisphere". (Ed. A. W. Young). Academic Press, London, pp. 33-64.

Ellis, H. D. and Young, A. W. (1990). Accounting for delusional misidentifications. British Fournal of Psychiatry, 157, 239-248.

Heilman, K. M. (1979). Neglect and related disorders. In "Clinical Neuropsychology", (Eds K. M. Heilman and E. Valenstein). Oxford University Press, New York, pp. 268-307.

Joseph, A. B. (1986). Focal central nervous system abnormalities in patients with misidentification syndromes. Bibliotheca Psychiatrica, 164, 68-79.

Joseph, A. B. (1987). Delusional misidentification of the Capgras and intermetamorphosis types responding to clorazepate. Acta Psychiatrica Scandinavica, 75, 330-332.

Kapur, N., Turner, A. and King, C. (1988). Reduplicative paramnesia: possible anatomical and neuropsychological mechanisms. Journal of Neurology, Neurosurgery and Psychiatry, 51, 579-581.

Lewis, S. W. (1987). Brain imaging in a case of Capgras' syndrome. British fournal of Psychiatry, 150, 117-121.

Luaute, J. P., Bidault, E. and Thionville, M. (1978). Syndrome de Capgras et organicité cérébrale: a propos d'une malade étudiée par un test de reconnaissance des visages et par la scanographie. Annales Medico-Psychologiques, 5, 803-815.

Morrison, R. L. and Tarter, R. E. (1984). Neuropsychological findings relating to Capgras' syndrome. Biological Psychiatry, 19, 1119-1128.

Shraberg, D. and Weitzel, W. D. (1979). Prosopagnosia and the Capgras' syndrome. Fournal of Clinical Psychiatry, 40, 313-316.

Tzavaras, A., Luaute, J. P. and Bidault, E. (1986). Face recognition dysfunction and delusional misidentification syndromes (DMS). In "Aspects of Face Processing" (Eds H. D. Ellis, M. A. Jeeves, F. Newcombe and A. Young). Martinus Nijhoff, Dordrecht, pp. 310-316.

Young, A. W. and Bruce, V. (1991). Perceptual categories and the computation of "grandmother". European Fournal of Cognitive Psychology, in press.

Young, A. W., Hay, D. C. and Ellis, A. W. (1985). The faces that launched a thousand slips: everyday difficulties and errors in recognizing people. British Journal of Psychology, 76, 495-523.

Young, A. W., Ellis, H. D., Szulecka, T. K. and de Pauw, K. W. (1990). Face processing impairments and delusional misidentification. Behavioural Neurology, 3, 153-168. 


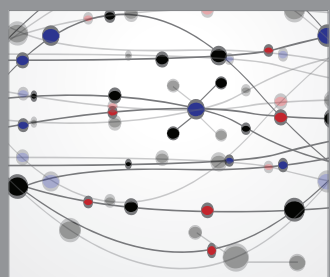

The Scientific World Journal
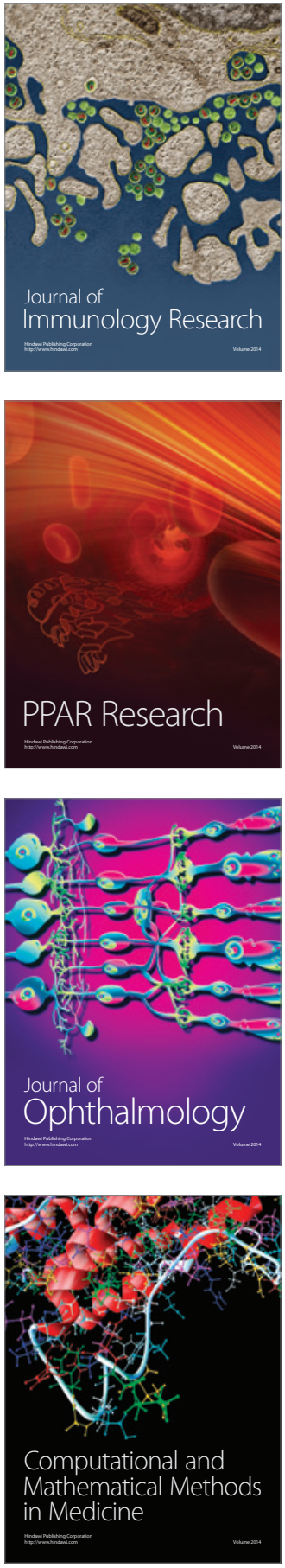

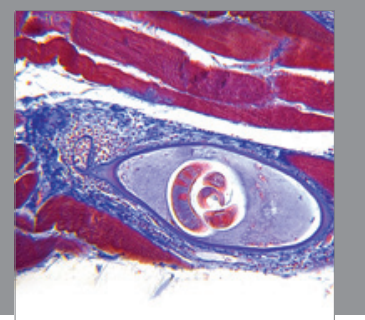

Gastroenterology

Research and Practice
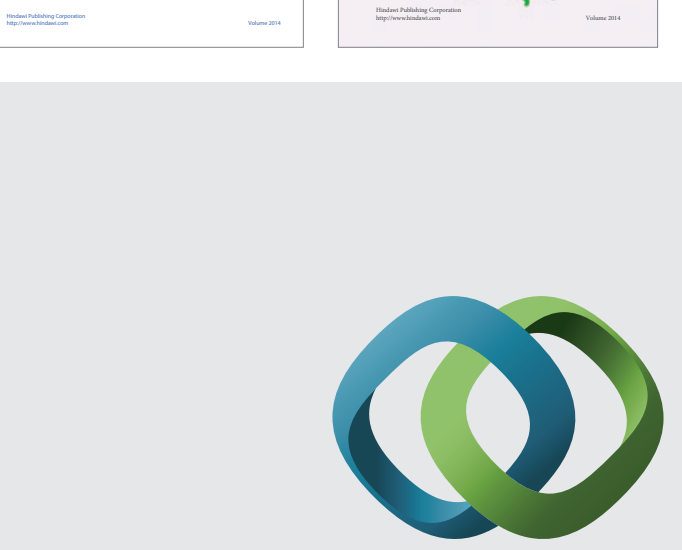

\section{Hindawi}

Submit your manuscripts at

http://www.hindawi.com
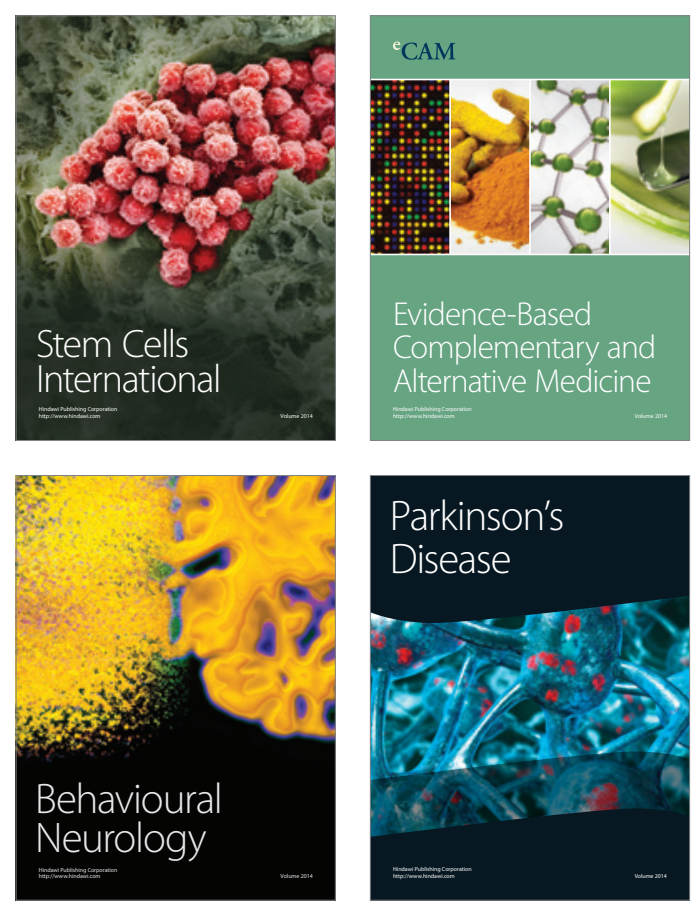

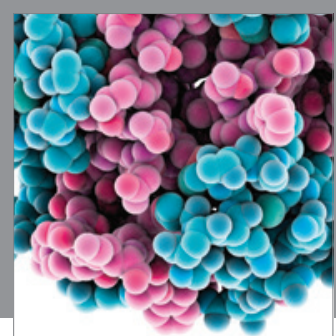

Journal of
Diabetes Research

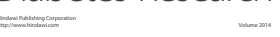

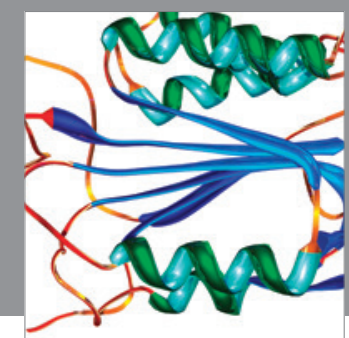

Disease Markers
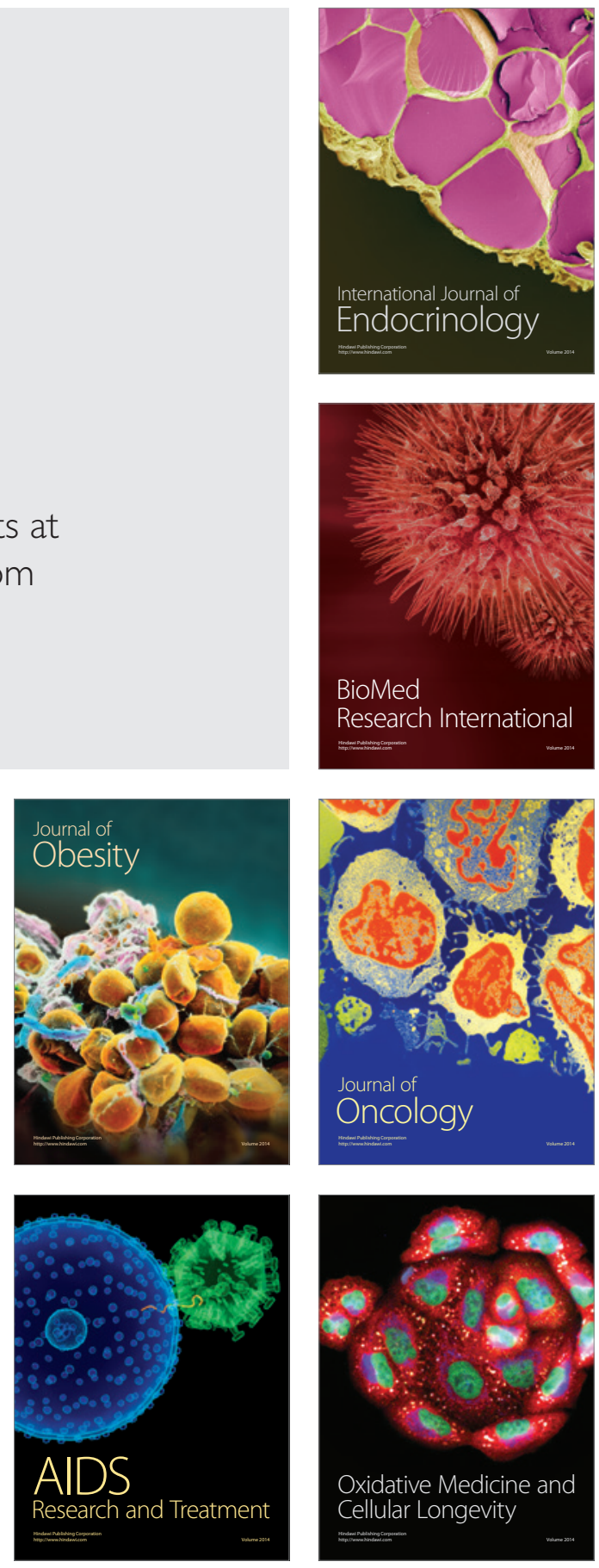